\title{
The Sultanate of Oman City Transportation in the Sharing Economy: Problems for Sustainable Development
}

\author{
Omran Abdullah Al-Mukhini, Adela P. Balasa, and Shima Ibrahim Al Maqbalia
}

\section{ABSTRACT}

This research analyzed the transportation issues in Oman towards the economic development sustainability of the country. The primary data used in this research by doing the activity of a questionnaire. The secondary data was collected through books, articles, online sites, and journals. The study resulted that the transportation improvement is effective to enhance the economic development in Oman. The improvements in the transportation sector are very effective for the provision of more employment to the people in Oman and enhance the logistics system efficiency. In addition, there will be the improvement in the production capacity of the companies in accordance with the increase in the transportation system and it leads the economic development of Oman. The adoption of train facilities is an asset for Oman to improve the transportation system effectiveness in the future for the economic growth development. Furthermore, the improvement in the sustainability is the best solution for the improvement of the transportation system sustainability in Oman. The strategy of enhancing the transportation activities will support Oman to enhance its economic development. The strategy of adopting the latest technological advancements is supportive for the transportation industry in Oman to overcome the challenges related to the technological advancements. The strategy of improving the infrastructure of Oman is most effective for the improvement of the transportation system in Oman.

Keywords: development, and infrastructure, economic growth, logistics system, sustainability, transportation system.

\section{INTRODUCTION}

In terms of economic sustainability and the development of a country, transportation is the most essential element [1]. The economic development of the country is directly influenced by the improvement of the transportation sector. An efficient transportation sector is supportive for the country to provide more employment to the people, enhance the educational level of people, reduce the air pollution, enhance the economic stability of the country, strengthen the financial stability of each person, save energy, reduce the consumption of energy, improve the effectiveness of logistics system, protect the environment, and enhance the business growth of the companies.

The sustainable development of the country is mainly focused on economic development, and it is closely associated with the development of the transportation system [2]. In Oman, the present situation is there is weakness in the transportation system, and it is essential to improve the strength of the transportation system for the betterment of economic development as well as sustainable development. The vision of 2040 of Oman is mainly focused on the improvement and development of the transportation system, and it will contribute to enhance the effectiveness of the transportation industry and lead to achieve a higher level of economic development for the country. fluctuation, etc.

\author{
Submitted : August 11, 2021 \\ Published : September 04, 2021 \\ ISSN: 2507-1076 \\ DOI: $10.24018 /$ ejbmr.2021.6.5.1052 \\ Omran Abdullah Al-Mukhini \\ B.A student the Logistics Management \\ department, International Maritime \\ College Oman, Sohar, Oman. \\ (e-mail: 03192-14@imco.edu.om) \\ Dr. Adela P.Balasa \\ Assistant Professor -Economic Science, \\ Logistics Management, International \\ Maritime College Oman, Sohar, Oman. \\ (e-mail: adela@ imco.edu.om) \\ Shima Ibrahim al Maqbalia \\ Assistant Lecturer, Logistics Management \\ Department, International Maritime \\ College Oman, Sohar, Oman. \\ (e-mail: Shaimaa @ imco.edu.om) \\ *Corresponding Author
}

\section{A. Background of the Research}

The purpose of this research is to analyze the transportation issues in Oman towards the economic development sustainability of the country. Transportation has an important role in the economic development of a country and the issue in transportation causes problems for sustainable development [3]. There are various types of challenges and problems that the transport sector is currently facing in Oman and these will disrupt the mobility of transportation within the entire Sultanate that will slowdown Oman's economic development. The most important challenges facing the transportation industry in Oman are technological advancements, government regulations, employment laws, workforce management, transportation costs, and oil price

The sustainability of the transportation system is effective for the improvement of the economic development of the country [4]. Moreover, the issues in the transportation system cause the problem for the country towards the economic development. Oman is a country mainly focused on the oil sector as a prime source of revenue. Hence, Oman is taking an interest in income diversification by focusing on the improvement of other sectors especially the transportation sector. Hence, the government is taking an interest in the development of transportation by providing the best facilities and enhance the effectiveness of the transportation system for 
the improvement of economic development.

\section{B. Statement of the Problem}

Some of the major issues in the transportation sector of Oman are considered as the changes in technology, employment issues, government regulations, transportation costs, employment laws, and workforce management [5]. In this case, the government should provide the maximum support to enhance the effectiveness of the transportation system and it will help to solve most of the problems related to the transportation industry and contribute to enhancing the economic stability in Oman. The identification of the problems faced by the transportation sector in Oman will be effective to solve the problems related to the transportation industry and it will contribute to enhancing the economic development of Oman.

One of the problems in Oman is that the country is entirely focusing on the oil sector sources for revenue and the decrease in oil price will create an economic crisis for the country. So, the strategy of income diversification is focused on by Oman government to enhance economic stability. In this case, the improvement of the transportation sector will support Oman government to improve the sustainability of the economy and achieve better economic growth. Moreover, if transport issues keep increasing throughout the Sultanate of Oman, there will be huge disruptions in achieving Oman's economic development. To attain Oman's vision of achieving economic growth, the government needs to focus on improvement.

\section{Research Questions}

-Main question:

- What effective strategies do government and private sectors design to sustain and develop the modes of transportation throughout the Sultanate of Oman?

-Sub questions:

- What are the main problems that Oman's transportation sector currently facing?

- What is the most sustainable mode of transportation used in Oman?

- Why does sustainability in the transport sector impact Oman's macroeconomy?

- How does sustainability work to revive Oman's transportation sector?

\section{Research Objectives}

- Identify the problems Oman's transportation sector is facing.

- Apply new transport solutions to strengthen transport sustainability in Oman.

- Analyze the impacts of transport sustainability as a highlight of Oman's economic growth.

- Evaluate the impacts of transport sustainability as an engine to Oman's economic development.

\section{E. Scope of the Study}

This research is focused on the topic of transportation and famous cities like Muscat, Salalah, Sohar, and Sur are focused on this research. Transportation in cities is mainly specified in this research and all types of vehicles in the cities are involved in this study. There are different types of vehicles involved in transportation sector and the transport vehicles like containers, public and private transport, ships, and aero plane are involved in this study. Hence, this research will give the scope of sustainability of transportation system and its impact on the economic development of Oman. Also, the strategies followed by the government to encourage the transportation system will be specified in this research.

\section{F. Justification of the Research}

This research is focused on the topic of transportation issues in Oman and their impact on economic development sustainability. Hence, the improvement in transportation sector will be a motive for the country to improve the economy and sustain economic development. Moreover, the improvement in the transportation system will support to decrease the level of air pollution and support to sustain environmental protection. In addition, the provision of better transportation facilities will support to improve the effectiveness of society and enhance the people satisfaction.

The improvement in the transportation system supports the companies to enhance their production capacity and improve the economic growth of the country. Moreover, the improvement in infrastructure will support enhancing the effectiveness of the transportation sector in Oman and contribute to enhancing the sustainability of economic growth. In addition, sustainability is effective for enhancing the infrastructure, decrease the transportation cost, promotes creativity and innovation, and enables businesses to grow. The strategy focuses on the improvement of the transportation system in Oman in order to achieve Oman's economic sustainability.

\section{G. Limitation of the Research}

One of the main limitations of this research is considered as the collection of relevant data for this research. The topic of this research is peculiar, and it is very difficult to obtain the relevant easily. Consequently, the researcher selected many books, articles, online sites, and journals to collect the relevant data for this research. Another limitation of this research is due to Covid-19 it is not possible to distribute the questionnaire to the people individually. Hence, the researcher planned to upload the questionnaire on the internet, and it will help to obtain the questionnaire data. Moreover, this research is focused on the transportation system in the main cities like Muscat, Salalah, Sur, and Sohar of Oman; and it is another limitation of this research.

\section{$H$. Significance of the Research}

This research is effective to understand deeply the impact of the transportation system on the economic development of Oman. There are different types of transportation systems are available in Oman and this research will specify all these like air, sea, and road. Moreover, there are lots of issues are facing the transportation sector in Oman and this research will specify it. In addition, some of the strategies are effective for the transportation sector to enhance the effectiveness of the transportation system and it will lead to improving the sustainability of economic development. So, these details will be specified in this research. Furthermore, the improvement of the transportation system will help to enhance environmental protection, enhancement of social development, and improve the economy of the country. So, this research will give a clear picture of the need for 
improvement of the transportation industry for a country towards the sustainability of economic growth.

\section{LITERATURE REVIEW}

\section{A. Transportation and Economic Development}

Transportation system development is effective for the country to enhance the effectiveness of the national economy by increasing the provision of many supportive activities [6]. The transportation improvements contribute to providing various types of employment opportunities to the local citizen and it will contribute to solve the problem of unemployment and consequently contribute to enhance the national economic growth. In addition, the improvement in the transportation system supports the businesspeople to perform their business activities efficiently and contribute to enhancing the national economy. Furthermore, the companies can enhance their production capacity with the support of the availability of an efficient transportation system and it will contribute to enhancing the financial stability of the company as well as the nation's financial credibility.

The improvement in the transportation system contributes to the sustainability of the transportation system and enhances the efficiency of the transportation industry [7]. Moreover, the availability of public transportation as part of transportation improvement will help the local people to make their local trips efficiently and enhance the people comfortable and contribute to enhancing the country's economic growth. In addition, the improvement of transportation is directly involved with the improvement of road infrastructure of the country and it will contribute to move for more vehicles without any traffic and contribute to enhance the effectiveness of the transportation sector and directly contribute to the economic development of the nation.

\section{B. Economic Importance of Transportation}

Development is considered as the improvement of the welfare of the society through the factors like economic, political, and social [8]. Hence, the improvement in the transportation system will be effective for the society to improve the human capital's educational levels and income. The improvement in educational level will contribute to improve the lifestyle of the people in a country and contribute to enhancing the economic development of the nation through the achievement of better jobs in their life. In terms of socioeconomic context, there is an important role in transportation system development.

One of the important elements essential for the development of the transportation system is considered as the improvement in the infrastructure of the country [9]. The infrastructure and managerial expertise directly influence the effectiveness of the logistics transportation system. Towards the improvement of the national economy, the transportation sector is the important sector. The high density of transportation infrastructure is directly associated with the economic development level of the country. Once the transportation systems are effective and efficient, they will provide social and economic opportunities and benefits which results in positive multiplier effects like employment, better accessibility to markets, and additional investments.
In case the transportation system is deficient in terms of reliability or capacity it will cause economic costs like the missed or reduced opportunities and a decrease in quality of life [10]. But, at the aggregate level, an effective transportation system is supportive to reduce the costs in various economic sectors. Likewise, the inefficient transportation system causes costs to increase. The provision of low-cost transportation infrastructure to the people is effective for enhancing customer satisfaction and improve the economic development of the country. The most important element for the development of countries economy is the transportation system because it is the basic element for society and economic development.

\section{Economic Opportunities and Transportation}

The development of transportation is considered as one of the strategic tools for growing economic opportunities [11]. In each state of social development, the specific transportation technology has been adopted or developed and it will impact the economic development opportunities. Economic cycles are closely related to different types of innovations like the example of transportation. Hence, the improvement in specific transportation technology is supportive of the achievement of economic development.

\section{1) Seaports}

Seaports are considered as one of the most effective transportation systems in Oman and it would be effective to contribute towards economic development [12]. Seaport is most effective for the countries to enhance the trade between other countries and contribute to enhancing the economic growth. In the beginning stage of business expansion, most of the countries are followed seaport transportation systems and it supported to improve the business growth and improvement in economic growth. The geographical structure of Oman is very supportive of the development of seaport transportation activities and it enhances the business development and improves the economy of Oman. Hence, the improvement in seaport transportation facilities will be effective for Oman to enhance its economic development.

\section{2) Railways}

One of the best transportation systems is railways and it will support transport the of goods from one place to a longer place at a lower price [13]. The main advantage of the railway transportation system is that it would be supportive for the people to travel from one place to another at a lower price along with more comfortable. Similarly, there is a goods train available in railways and they will transport only goods from one station to another station and it is the very effective transportation system for the country to enhance the economic development. Moreover, the implementation of the railways' transportation system will be effective for the countries that have railway transportation systems to improve their business growth and enhance economic development. Hence, it is suggested a country like Oman should encourage the railway transportation system for the achievement of better economic development.

\section{3) Roads}

The improvement in the road infrastructure is one of the effective tools for the countries to enhance the effectiveness of road transportation system and support to improve the 
business growth and enhance the economic growth [14]. Moreover, the development inroads are effective for the people to drive their vehicles safely and without any traffic. In addition, the improvement in road transportation system supports the companies to transport their finished goods and raw material efficiently and contribute towards the improvement of business activities. Hence, the improvement in the road transportation system supports the countries to enhance their economic growth.

\section{4) Airways}

The development of airways supported to enhance the effectiveness of transportation system and it directly contributes to improving the trading between the countries in a fast manner [15]. Most of the emergency goods transport with the support of airways in the form of cargo. The airways are very effective to reach the items at the destination at the earliest and improve the business growth. In addition, the people are enjoying their journey with the support of the airways transportation system. It is easy for people to cover a long distance in the shortest time with the support of airways facilities. In addition, the improvement in airways is supportive for the countries to enhance the business activities with other countries efficiently.

\section{Problems Face by Oman Transportation Sector}

The transportation sector and logistics industry are some of the non-oil competent for Oman in terms of increases the economy [16]. Hence, the logistics and transportation sector contribute 5\% GDP growth of Oman [17]. At present, the growth of the transportation sector in Oman is increasing and it contributes towards the creation of new jobs for the people. However, there are lots of challenges and issues are facing the transportation sector in Oman. Therefore, the government and stakeholders should make sure that the growth of the transportation sector should be sustained for better economic development. Moreover, the Oman government created ASYAD, which is an umbrella organization in terms of synergizing the transportation and logistics stakeholders' activities and expand the capabilities to meet the demands of the future market.

\section{1) Technological advancements}

The advancement in technology is one of the major issues or challenges faced by the transportation sector in Oman [18]. It is difficult for the business to adopt these technological advancements for future growth. The logistics and transportation sector is required to set up intelligent and integrated facilities incorporating the next-generation features, active collaboration and seamless business transactions among the stakeholders, capability to handle the entire types of cargo with special requirements, adoption of best practices, and learning from industry pioneers. Hence, it is required more efficient storage space along with the movement of cargo. So, all the main technological-related challenges are faced by the logistics and transportation sector in Oman.

\section{2) Employment laws}

Oman is highly focused on the policy of Omanization and it is one of the challenges for the transportation sector [19]. Hence, Oman is increasing the number of Omani nationals in the private and public sector and it leads to some of the issues for the transportation sector. Most of the expatriates working in the transportation sector are highly qualified and they are working for a reasonable salary. The Omanization process created a problem for the transportation sector companies to provide training to the Omani people and it is increasing the financial liability of the companies. Moreover, the absence of trained employees in the transportation sector is another challenge for the transportation sector companies in Oman.

\section{3) Government regulations}

There are government policies and regulations are implemented in the transportation sector and these are effective for the transportation sector to do transport activities efficiently [20]. But some of the rules and regulations are not easy for the transportation sector and they have to follow strict rules and regulations. Some of the government regulations pertaining to the logistics and transportation sector are setting up special economic zone, customs regulations, relaxation in ownership of foreign entities' business, and tax breaks, etc. So, the transportation and logistics sectors stakeholders are demanding the government to give relaxation in terms of arranging pre-clearance for cargo, reduce the inspection number, manage risks, and improve the process. So, the provision of little relaxation for these aspects will support the transportation sectors to enhance their business effectiveness.

\section{4) Transportation costs}

The rising transportation cost is one of the main problems faced by the transportation and logistics sector in Oman due to the rise in fuel costs [21]. In this case, the logistics companies have issues in the budget to ship the items without profits and it will directly impact the financial stability of the logistics and transportation sector companies. Hence, the transportation and logistics sector companies have to demand higher shipping prices from the customers, and it will increase the customers' costs. Hence, the transport and transportation companies should find an alternative solution to solve this problem and improve the effectiveness of the transportation sector in Oman. Hence, the strategies like autonomous tracking, artificial intelligence, and the adoption of the latest technology will support transportation and logistics sector companies to reduce transportation costs and enhance customer satisfaction.

\section{5) Workforce management}

It is essential that the presence of highly qualified employees is the asset for any companies or industries to achieve higher success [22]. There are issues facing by the transportation and logistics sector companies in terms of the skills and talents of their workforce. Some of the transportation and logistics companies are adopted robotics and drone technology in order to overcome this challenge. Hence, it would be effective for increase the productivity and effectiveness of transportation and logistics sector. Moreover, the provision of proper training will support to enhance the effectiveness of transportation sector and improve their business growth.

\section{E. Transport Solutions to Strengthen Transport Sustainability}

\section{1) Improve freight efficiency}

The strategy of improving freight efficiency is one of the 
effective points to enhance transportation sustainability in Oman [23]. In this case, the improvement in freight efficiency will support increasing the consumption level on the individual level along with a more globalized economy towards transportation sustainability. One of the examples is the transportation of a product by freight it will increase the speed of action and improve the business growth of the country along with improvement in transportation sustainability.

\section{2) Increase in public transportation}

The strategy of improving the availability of the public transportation system is one of the important aspects to enhance transportation sustainability in Oman [24]. The provision of public transportation facility it will support the people to use the public transportation facilities and they can avoid their vehicle for the normal journey. Moreover, the implementation of more public transportation will support saving energy and protect the environment from pollution. There will be a decrease in the usage of fuel while encouraging the public transportation facility and it will lead to save energy and achieve a higher level of economic development. Hence, the strategy of implementing more public transportation will support improving the effectiveness of transportation sustainability.

\section{3) Improve electric vehicle infrastructure}

The strategy of improving the electric vehicle infrastructure is one of the best solutions to improve transportation sustainability in Oman [25]. The main advantage of electric vehicle infrastructure is that it will reduce air pollution and protect the environment. In addition, the transportation cost will be less while using the electric vehicle. Moreover, the usage of electric cars will support to enhance the economic development of Oman by increasing the amount of exporting fuel. So, the concept of the introduction of more electric vehicles will support improving the transportation sustainability in Oman by reducing transportation costs and reduce the level of air pollution.

\section{4) Railways}

The strategy of introducing railway facilities is more effective to improve transportation sustainability in Oman [26]. The advantage of the railway is that the transportation cost will be very less. Moreover, the railway is very effective to transport a huge amount of goods from one station to another station. In addition, the speed of railways is comparatively higher than trucks and it will help to increase the business growth of the companies. Also, the people can make their journey comfortable with the support of the railway. Hence, the provision of railway facilities will be more effective for Oman to improve transportation sustainability by reducing transportation costs and speed of access.

\section{5) Improvement in road infrastructure}

The strategy of improving the infrastructure of roads in Oman is most effective to improve transportation sustainability [27]. In this case, the government should build more highway roads and it will support to reduce the traffic problem for the people and improve the business growth. In addition, the increase in the number of roads will support reaching the destination in the shortest way and it will support decrease transportation costs. Moreover, the increase in roads will support accommodating more trucks and vehicles on road without any issues and enhance transportation sustainability. Hence, the improvement in road infrastructure will support enhancing the effectiveness of transportation sustainability by reducing traffic issues and decrease transportation costs.

\section{F. Transportation Sustainability and Economic Development}

The improvement in transportation sustainability is effective for enhancing the economic growth for Oman [28]. Transportation sustainability is leading the companies to enhance their business growth by increasing the supply chain activities efficiency. Moreover, the companies can receive the raw material on time without any issues with the support of transportation sustainability and it will contribute to enhancing the economic development of the country by increasing the production capacity of the company. In addition, the improvement in transportation sustainability supports the companies to transport the finished goods from the factory to the warehouse without any issues and increases the effectiveness of availability of the products in the market So, the improvement in transportation sustainability supports the country to enhance economic growth.

The improvement in transportation sustainability supports the common people to travel without any issues [29]. The utilization of public transport will help the people to decrease the transportation cost and improve the comfort of the journey. In addition, the improvement in transportation sustainability supports to decrease in environmental pollution by decreasing the number of private vehicles. Moreover, transportation sustainability helps the government to enhance the economy through the concept of income diversification. Therefore, the improvement in transportation sustainability supports Oman government to enhance their economic strength and compete with other countries efficiently.

The improvement in transportation sustainability supports enhancing international trade competency [30]. The transportation modes like road, sea, and air are commonly used in Oman for transportation purposes and the improvement in these modes will encourage improving the efficiency of the business. The business improvement is very effective for Oman to enhance national competitiveness. In addition, the improvement in transportation sustainability will support providing more employment opportunities to the local citizen and it will help to enhance the per capita income of citizens and directly contribute to achieving a higher level of economic development.

\section{RESEARCH METHODOLOGY}

\section{A. Research Framework}

In research, a theoretical framework is a structure that holds the theory to support the study inquiry. There are theoretical and conceptual research frameworks are available. Moreover, the research framework is describing and introducing the theory which is explaining the research problem as per the existing research study. In addition, the research framework supports determining the proper research method and approach by considering the given situation. 
Furthermore, the research framework supporting the research to plan and structure the research activities as per the scope and breadth of the research question. There are three important steps involved in the research framework like identify the key concepts, explain, and evaluate the relevant theories, and measure the fit of research. A questionnaire, case study, interview, experiments, observation, and group discussion are the research methods.

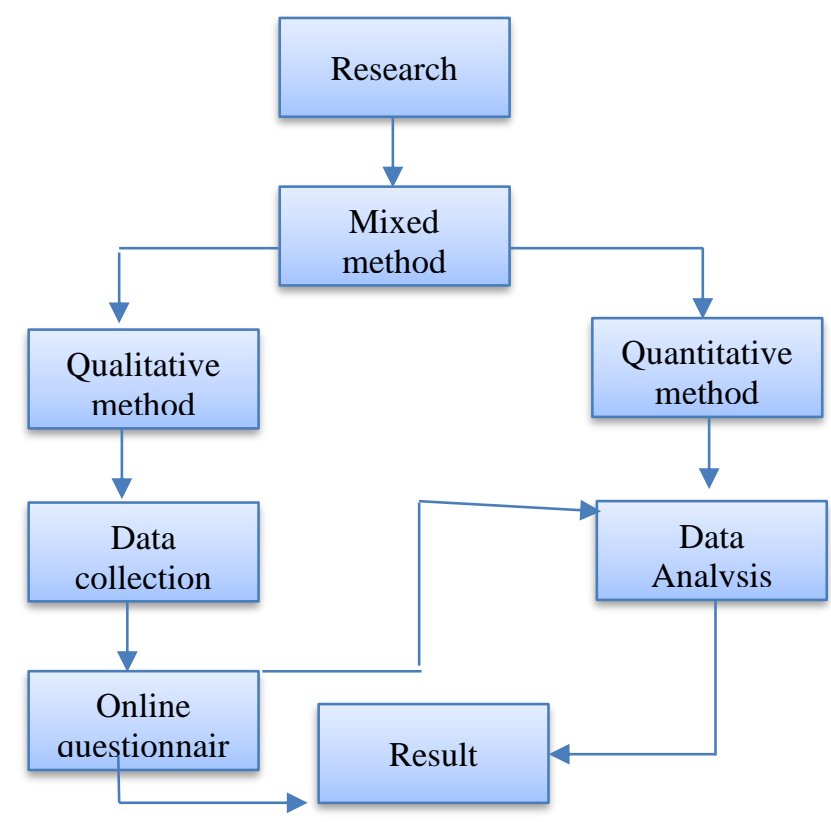

Fig. 1. Research Framework.

\section{B. Research Approach}

The two types of important research approaches are called qualitative and quantitative, and another one is the mixed approach. Most of the researchers are using different types of research approaches by considering the nature of the research. In addition, the researcher must select the proper research approaches to make the research more powerful and effective. The specialty of quantitative research is that it involved numerical and statistical-based data and it is suitable for research that is focused on numerical and statistical data. The questionnaire data will be mostly used in the quantitative research approach.

On the other hand, qualitative research has the specialty like it will use the participants' perceptions and open-ended communications [31]. In addition, there will be a huge database used in the qualitative research approach and it is a longer process. However, the mixed approach is the combination of the qualitative and quantitative research approaches and it will have the characteristics of both approaches. This research is following the quantitative and qualitative research approach because it is easy to handle and using the questionnaire and interview data.

\section{Sampling}

The sampling size of this research is 120 participants like 40 participants each from Sohar, Salalah, and Muscat. The researcher will upload the questionnaire to a Google site and focus on the response of 120 participants. A simple random sampling technique is followed by the researcher in this research.

\section{Data Analysis}

The researcher is following the concept of charts and tables in terms of doing the data analysis. Moreover, the charts and tables will support provide more details about the remarks of the participants on each question in this research. The interview question and data will be analyzed in a questionand-answer format. The researcher interviewed online by focusing on the manager named Mr. Hamed Al-Senaidi, working in DAlilee Delivery and Cargo Service on the phone number +968 92010106, and the manager named Mr. Rajesh Kumar, working as a shift manager in Oman India Fertilizer Company SAOC on the phone number +96894306268.

The data analysis steps involved in the quantitative method is that the researcher is collected the questionnaire data through an excel sheet. After that, the average of the data will be identified by using the mean statistical tool. Hereafter, the researcher will make the bar charts by using the data collected from the questionnaire. Hence, the data will be analyzed with the support of tables and charts. On the other hand, in terms of the qualitative method, the data analysis will be carried like the researcher will write the question asked to the interviewee and after that, the answer will write under each question.

\section{DATA ANALYSIS AND FINDINGS}

\section{A. Participants Profile}

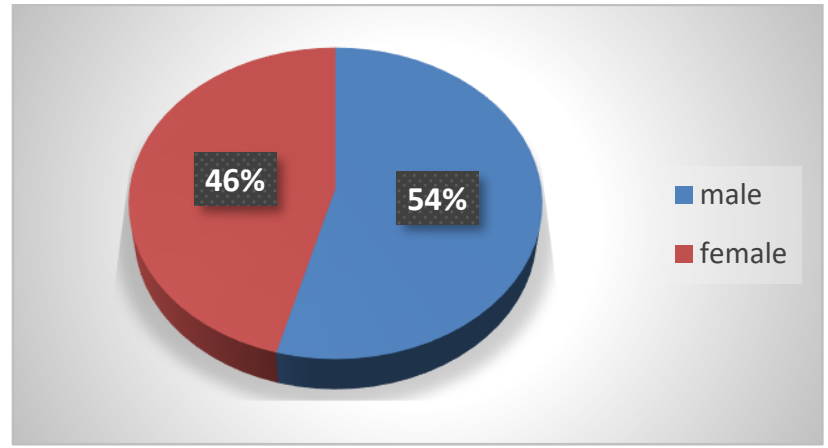

Fig. 1. Gender.

The details of the participants in terms of their gender are given in the above table and figure. It has been observed that the number of male participants is more in this research because male participants are $54.2 \%$ and female participants are $45.8 \%$.

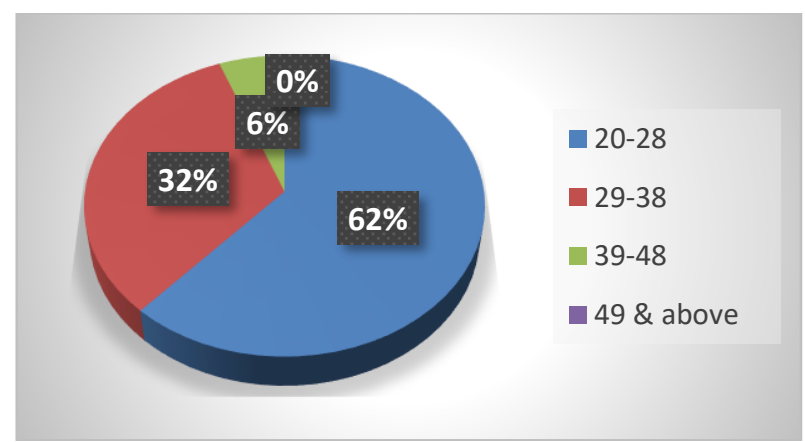

Fig. 2. Age.

The details of the age of the participants are shown in the above table and figure. It is observed that the majority of the participants belong to the age group of 20 to 28 by $61.7 \%$ and it is followed by the age group of 29 to 38 by $32.5 \%$. So, most 
of the participants were at a young age.

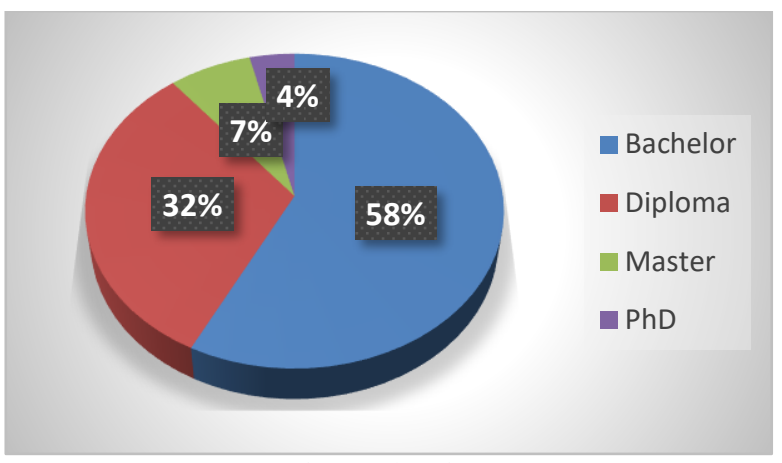

Fig. 3. Education.

The details of the educational qualifications of the participants are provided in the above figure and table. It is identified that more participants are graduates by having their strength of $57.5 \%$, followed by diploma like $31.7 \%$ and master by $7 \%$ and PhD holders by $4 \%$.

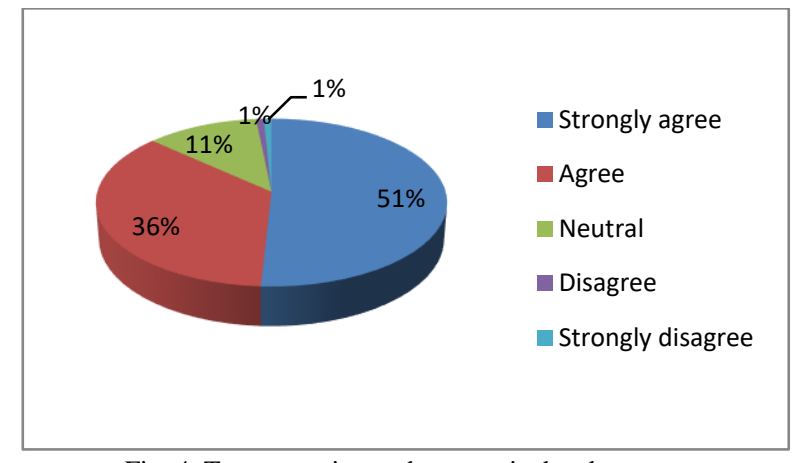

Fig. 4. Transportation and economic development.

On the point, transportation has an important role in the economic development of Oman, the opinion of the participants is given in the above table and figure and it found that $50.8 \%$ strongly agreed and $35.8 \%$ agreed. So, it is found that transportation has an important role in the economic development of Oman. Moreover, the improvement in transportation is effective to enhance the economic development in Oman.

Analysis on the point, transportation has an important role towards the economic development of Oman, and it identified that the improvement in transportation supports Oman to enhance their economic development.

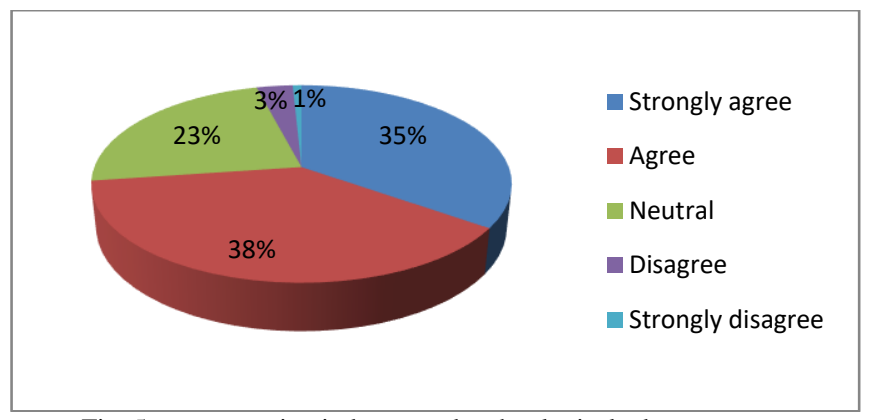

Fig. 5. transportation industry and technological advancements.

On the point, one of the most important challenges facing by the transportation industry in Oman are technological advancements, the remarks of the participants are shown in the above figure and table like $35 \%$ strongly agreed and
$38.3 \%$ agreed. Hence, it is identified that one of the most important challenges facing the transportation industry in Oman is technological advancements. Moreover, there are changes in technology every day and the advancement in technology is considered as the main challenge for the transportation industry in Oman.

Analysis on the point, one of the most important challenges facing the transportation industry in Oman are technological advancements, and it found that the increase in technological advances is creating challenges for the transportation industry in Oman.

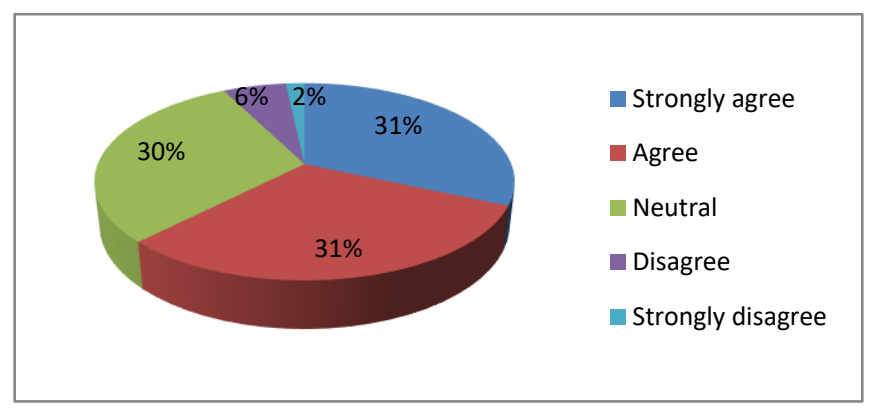

Fig. 6. Transportation sector and employment to the people.

On the point, an efficient transportation sector is supportive for Oman to provide more employment to the people and improve the effectiveness of logistics system, the remarks of the participants are like $31.7 \%$ strongly agreed, and $30.8 \%$ agreed; and it is shown in the above table and figure. So, it is illustrated that an efficient transportation sector is supportive for Oman to provide more employment to the people and improve the effectiveness of the logistics system. Moreover, the improvement in the transportation sector is very effective for the provision of more employment to the people in Oman and enhances the logistics system efficiency.

Analysis on the point, an efficient transportation sector is supportive for Oman to provide more employment to the people and improve the effectiveness of logistics system, and the development and improvement of transportation sector are helpful for the creation of many jobs for the citizen and improves the efficiency of logistics system.

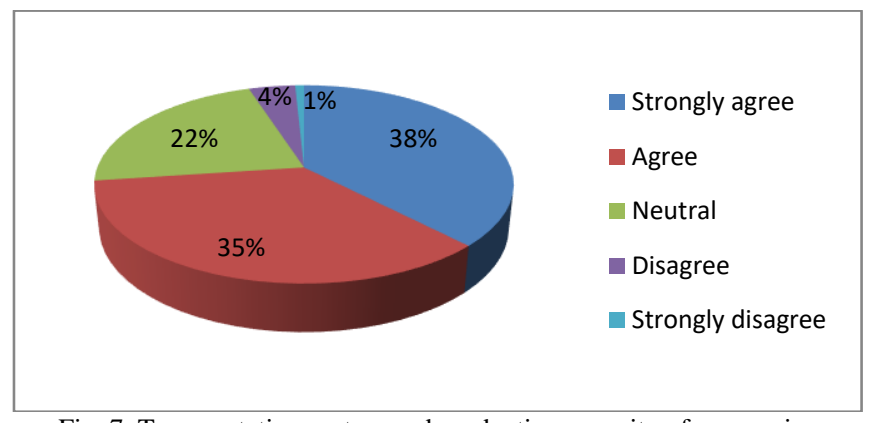

Fig. 7. Transportation system and production capacity of companies

On the point, the improvement of transportation system supports to increase the production capacity of the companies in Oman and contribute towards the economic development of the country, the opinion of the participants is $37.5 \%$ strongly agreed and $35 \%$ agreed. Hence, it is noticed that the improvement of the transportation system supports to increase in the production capacity of the companies in Oman and contributes towards the economic development of the 
country. Moreover, there will be an improvement in the production capacity of the companies in accordance with the increase in the transportation system and it leads the economic development of Oman.

Analysis on the point, the improvement of transportation system supports to increase the production capacity of the companies in Oman and contribute towards the economic development of the country, and the companies can enhance their products with the support of an increase in the transportation system and it will contribute to improving the economic development of Oman.

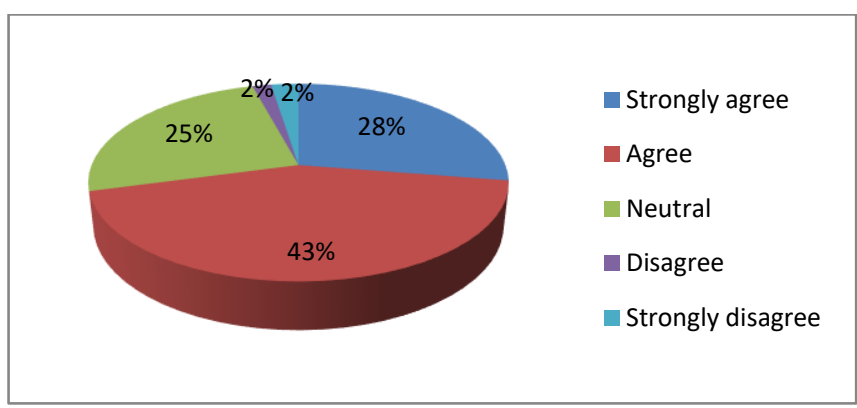

Fig. 8. Train facilities and transportation system.

On the point, the development of train facilities will support Oman in the future to enhance the effectiveness of the transportation system and improve the economic growth, $27.5 \%$ of participants are strongly agreed, and $43.3 \%$ agreed. So, it is identified that the development of train facilities will support Oman in the future to enhance the effectiveness of the transportation system and improve economic growth. Moreover, the adoption of train facilities is an asset for Oman to improve the transportation system effectiveness in the future for economic growth development.

Analysis on the point, the development of train facilities will support Oman in future to enhance the effectiveness of transportation system and improve the economic growth, and the improvement in train facilities will be a most effective asset for Oman in future towards the improvement of the transportation system and enhance the economic growth.

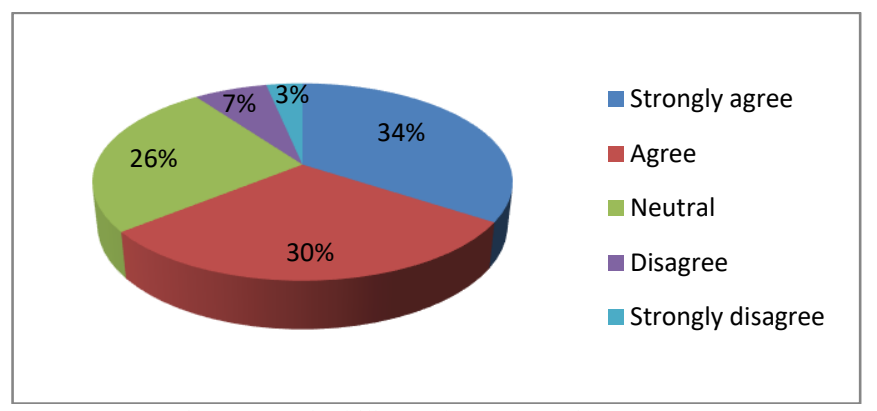

Fig. 9. Sustainability and transportation system.

On the point, the strategy of enhancing the sustainability is effective to enhance the transportation system sustainability in Oman, the remarks of the participants are shown in the above figure and table like $34.2 \%$ strongly agreed, and $30 \%$ agreed. Hence, it is observed that the strategy of enhancing sustainability is effective to enhance the transportation system sustainability in Oman. Moreover, the improvement in sustainability is the best solution for the improvement of the transportation system sustainability in Oman.

Analysis on the point, the strategy of enhancing sustainability is effective to enhance the transportation system sustainability in Oman, and the focus on the improvement of sustainability is effective to enhance the transportation system sustainability in Oman.

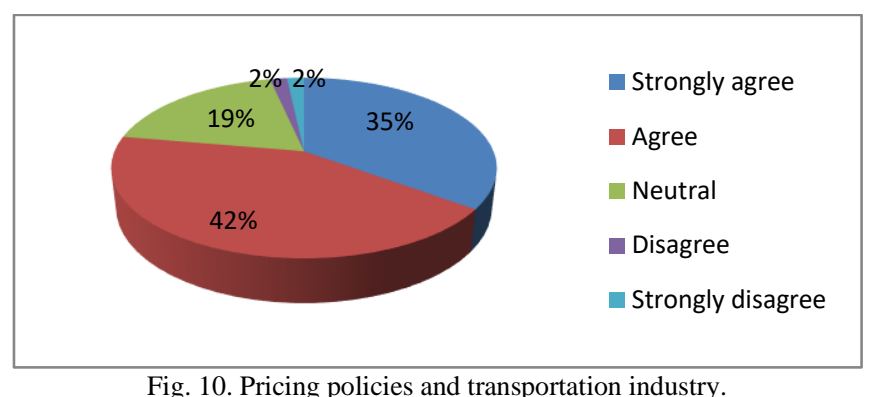

On the point, the strategy of pricing policies will support to reduce the operational cost for the transportation industry and contribute to improving the economic development of Oman, the remarks of the participants are $35 \%$ strongly agreed, and $42.5 \%$ agreed. So, it is found that the strategy of pricing policies will support reducing the operational cost for the transportation industry and contribute to improving the economic development of Oman. Moreover, it is easy to reduce the operational cost of the transportation industry with the support of effective pricing policies and it will support enhancing the economic growth of Oman.

Analysis on the point, the strategy of pricing policies will support to reduce the operational cost for the transportation industry and contribute to improving the economic development of Oman, and the focus on the implementation of effective pricing policies will support to improve the economic development of Oman through the process of decrease the operational cost of the transportation industry.

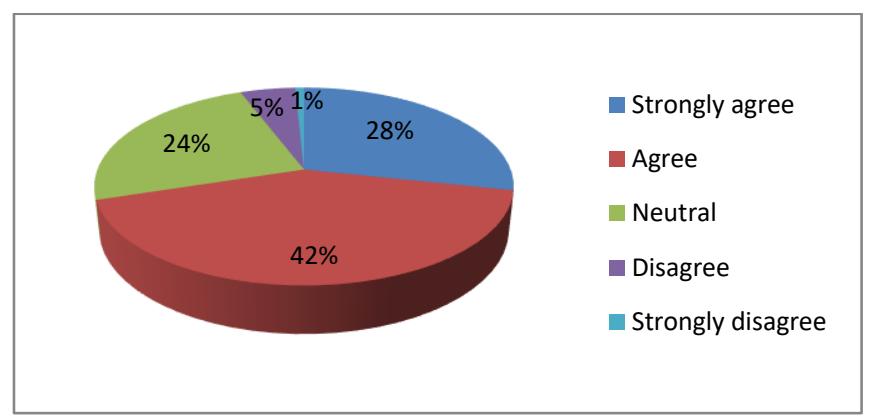

Fig. 11. Transportation system and infrastructure of Oman.

On the point, one of the important elements essential for the development of the transportation system is considered as the improvement in the infrastructure of the country, the opinion of the participants is $28.3 \%$ strongly agreed, and $41.7 \%$ agreed. So, it is identified that one of the important elements essential for the development of the transportation system is considered as the improvement in the infrastructure of the country. Moreover, the improvement in the infrastructure of Oman is effective to enhance the efficiency of the transportation system in Oman.

Analysis on the point, one of the important elements essential for the development of the transportation system is considered as the improvement in the infrastructure of the country, and the improvement in Oman infrastructure is most effective to improve the efficiency of the transportation system in Oman. 


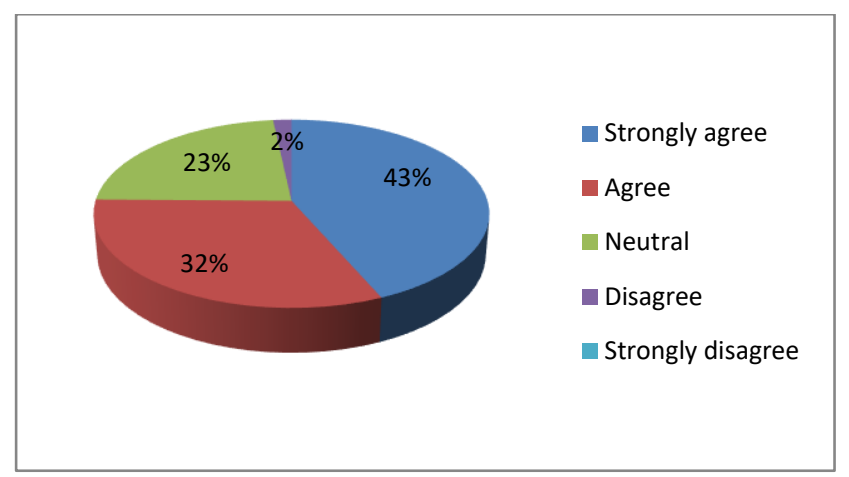

Fig. 12. Seaport and trade between other countries.

On the point, the seaport is most effective for the countries to enhance the trade between other countries and contribute to enhancing the economic growth, the opinion of the participants is $43.3 \%$ strongly agreed, and $31.7 \%$ agreed. So, it is observed that seaport is most effective for the countries to enhance the trade between other countries and contribute to enhancing the economic growth. Moreover, towards the improvement of trade between other countries seaport has an important role and it contributes to improving the economic growth of Oman.

Analysis on the point, the seaport is most effective for the countries to enhance the trade between other countries and contribute to enhancing the economic growth, and the improvement in seaport is most effective for Oman to enhance the effectiveness of trade between other countries towards the development of Oman economy.

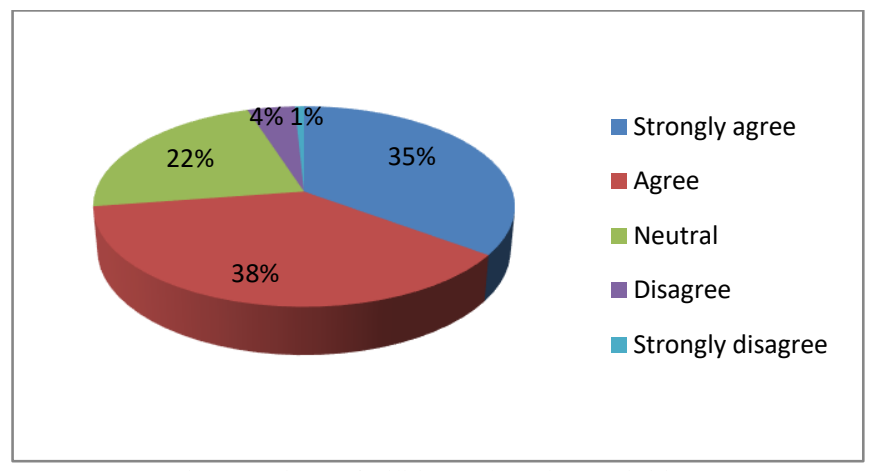

Fig. 13. Airport facilities and tourism activities.

On the point, the improvement in airport facilities will support the country to encourage the tourism activities and it will support to enhance the economic development, the remarks of the participants are 35\% strongly agreed, and $37.5 \%$ are agreed. Hence, it is identified that the improvement in airport facilities will support the country to encourage tourism activities and it will support to enhance the economic development. Moreover, to improve the tourism activities in Oman the improvement of airport facilities is supportive, and it will contribute to improving the economy of Oman.

Analysis on the point, the improvement in airport facilities will support the country to encourage the tourism activities and it will support to enhance the economic development, and Oman can improve the tourism activities with the support of improvement in airport facilities and it will support to improve the economic growth of Oman.

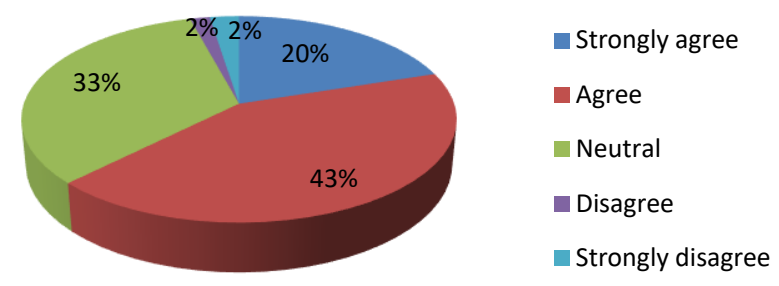

Fig. 14. Transportation and logistics sector companies with skills and talents of workforce.

On the punt, there are issues faced by the transportation and logistics sector companies in Oman in terms of the skills and talents of their workforce, the remarks of participants are $20 \%$ strongly agreed, and $42.5 \%$ agreed. Hence, it is illustrated that there are issues faced by the transportation and logistics sector companies in Oman in terms of the skills and talents of their workforce. Moreover, one of the most important problems for the transportation and logistics sector companies in Oman is the lack of the talents and skills of their employees.

Analysis on the point, there are issues faced by the transportation and logistics sector companies in Oman in terms of the skills and talents of their workforce, and the transportation and logistics sector companies should focus on the recruitment of highly skilled employees to enhance their operational efficiency.

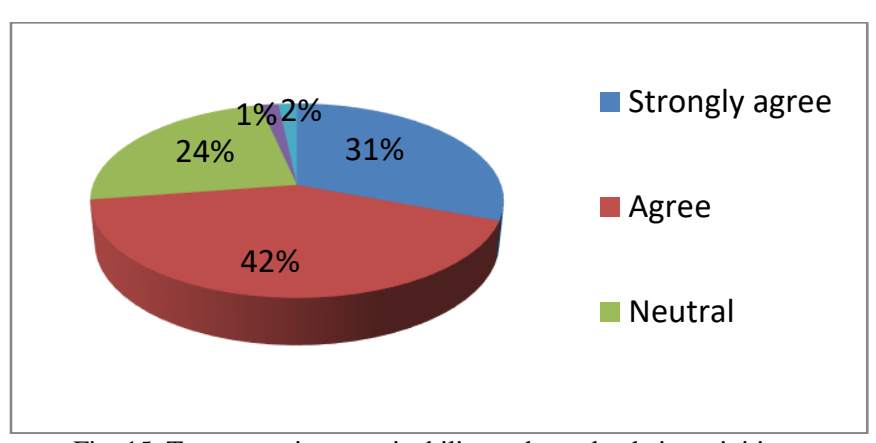

Fig. 15. Transportation sustainability and supply chain activities.

On the point, that transportation sustainability is leading the companies to enhance their business growth by increasing the supply chain activities efficiency, the remarks of the participants are $30.8 \%$ strongly agreed, and $41.7 \%$ agreed. Hence, it is observed that transportation sustainability is leading the companies to enhance their business growth by increasing the supply chain activities efficiency. Moreover, there will be an improvement in the supply chain activities with the support of an increase in transportation sustainability and this will support the companies to give the best output.

Analysis on the point, the transportation sustainability is leading the companies to enhance their business growth by increasing the supply chain activities efficiency, and the improvement in supply chain activities is very effective for the companies to enhance their business growth through the concept of transportation sustainability. 


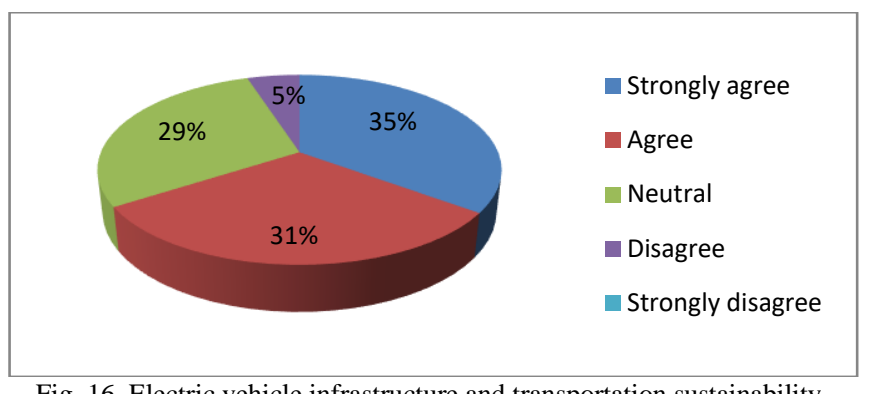

Fig. 16. Electric vehicle infrastructure and transportation sustainability.

On the point, the strategy of improving the electric vehicle infrastructure is one of the best solutions to improve transportation sustainability in Oman, the remarks of the participants are shown like $35 \%$ strongly agreed, and $30.8 \%$ agreed. Hence, it is observed that the strategy of improving the electric vehicle infrastructure is one of the best solutions to improve transportation sustainability in Oman. Moreover, the improvement in electric vehicle infrastructure is very effective for Oman to enhance the efficiency of transportation sustainability.

Analysis on the point, the strategy of improving the electric vehicle infrastructure is one of the best solutions to improve the transportation sustainability in Oman, and the improvement in electric vehicle infrastructure is most effective for the improvement of Oman transportation sustainability.

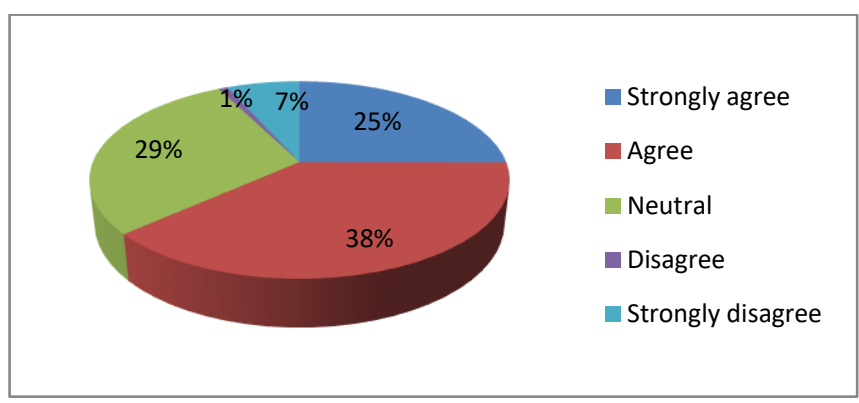

Fig. 17. Omanization and transportation sector companies.

On the point, the Omanization process created a problem for the transportation sector companies to provide training to the Omani people and it is increasing the financial liability of the companies, the remarks of the participants are $25 \%$ strongly agreed, and $38.3 \%$ are agreed. Hence, it is found that the Omanization process created a problem for the transportation sector companies to provide the training to the Omani people and it is increasing the financial liability of the companies. Moreover, there are issues for transportation sector companies due to the process of Omanization like the provision of training to employees and increasing the financial liabilities of the firms.

Analysis on the point, the Omanization process created a problem for the transportation sector companies to provide the training to the Omani people and it is increasing the financial liability of the companies and the process of Omanization is creating issues for transportation sector companies for the provision of training to the employees and it is increasing the financial liability of the firms.

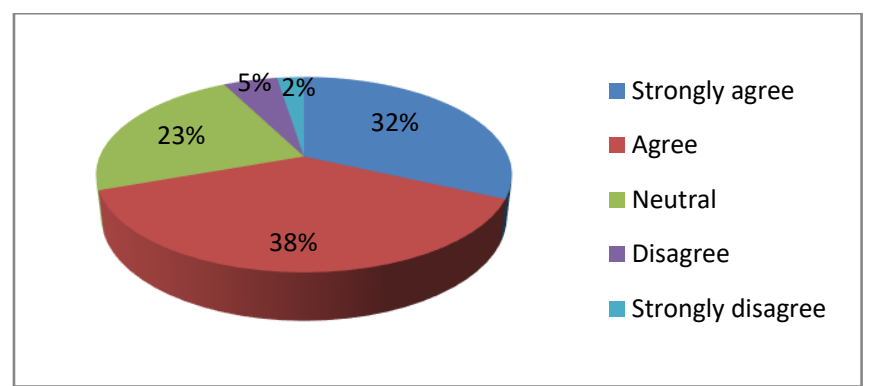

Fig. 18. Road transportation system and economic growth.

On the point, the improvement in the road transportation system supports Oman to enhance the economic growth, the remarks of participants are $31.7 \%$ strongly agreed, and $37.5 \%$ agreed. Hence, it is observed that the improvement in the road transportation system supports Oman to enhance economic growth. Moreover, there will be an improvement in the Oman economy due to the increase in the road transportation system.

Analysis on the point, the improvement in road transportation system supports Oman to enhance the economic growth, and the increase of road transportation system supports Oman to achieve a higher level of economic growth.

\section{B. Findings and Analysis}

Transportation has an important role in the economic development of Oman and its strategy to enhance the transportation activities that will support Oman's continuous economic development. In addition, one of the most important challenges facing the transportation industry in Oman are technological advancements, and the strategy to adopt the latest technological advancements that will support the transportation industry in Oman and to overcome the challenges related to its technological advancements. Moreover, an efficient transportation sector is supportive for Oman to provide more employment to the people and improve the effectiveness of the logistics system, and the strategy is focused on the improvement of the transportation sector which is sustainable for the provision of more jobs to the people in Oman and improves the efficiency of the logistics system.

The improvement of transportation system supports to increase the production capacity of the companies in Oman and contribute towards the economic development of the country, and the strategy of increasing the effectiveness of transportation system is supportive for the companies to enhance their production capacity and contribute to improving the economic development of Oman. Moreover, the development of train facilities will support Oman in the future to enhance the effectiveness of the transportation system and improve the economic growth, and the strategy to focus on the improvement and development of train facilities will be effective for Oman to enhance the transportation system efficiency in future and it will support to enhance the level of economic growth.

Oman's strong and effective transportation system strategies enhance sustainability throughout the Sultanate's transportation system. One among Oman's transport policies is the pricing strategy that supports the reduction of transportation operational costs yielding to the increase of Oman's sustainable economic growth. Few among the strong 
policies that served as an added value to effective and efficient mobility of the transport sector here in Oman are the construction of state-of-the-art transport infrastructures such as roads, transport terminals and the investment of public transportation such as the Sultanate's run bus services MWASALAT.

Seaport is most effective for the countries to enhance the trade between other countries and contribute to enhancing the economic growth, and the strategy to improve the efficiency of the seaport is most effective for Oman to enhance the trade between other countries towards the economic growth development. Moreover, the improvement in airport facilities will support the country to encourage tourism activities and it will support enhance economic development, and the strategy to improve the airport facilities is very effective for Oman to improve tourism and it will support improve the economic growth of Oman. Furthermore, there are issues faced by the transportation and logistics sector companies in Oman in terms of the skills and talents of their workforce, and the strategy to identify and recruit highly skilled workers that are effective and efficient to share their expertise on both "scientific and engineering know-how' to be able to provide flexible and cheap transportation for the Omanis to and from their workplace, markets, customers, etc.

Transportation sustainability is leading the companies to enhance their business growth by increasing the supply chain activities efficiency, the strategy of enhancing the supply chain activities as part of transportation sustainability is effective for the companies to improve their business growth in Oman. Moreover, the strategy of improving the electric vehicle infrastructure is one of the best solutions to improve transportation sustainability in Oman, and the strategy of improving the effectiveness of electric vehicle infrastructure is most effective to enhance transportation sustainability in Oman. Also, the Omanization process created a problem for the transportation sector companies to provide the training to the Omani people and it is increasing the financial liability of the companies, and the focus on the recruitment of skilled employees is effective for the transportation sector companies to have the talented employees and enhance their operational efficacy. Besides this, the improvement in the road transportation system supports Oman to enhance the economic growth, and the strategy to focus on the improvement of the road transportation system is very effective in Oman to attain its economic development.

\section{Interview}

The researcher conducted the interview online by focusing on the manager named Mr. Hamed Al-Senaidi, working in DAlilee Delivery and Cargo Service on the phone number +968 92010106, and the manager named Mr. Rajesh Kumar, working as a shift manager in Oman India Fertilizer Company SAOC on the phone number +96894306268 . Hence, the details of the interview are given below.

Q1. What are the main problems faced by Oman's transportation sector?

Ans: Some of the important problems facing the transportation industry in Oman are technological advancements, government regulations, employment laws, workforce management, transportation costs, and oil price fluctuation, etc.

Q2. What are the new transport solutions to strengthen transport sustainability and the economic development of Oman?

Ans: The strategies like the improvement in road management and improvement of the roads will support to reduce the traffic block and increase the number of more vehicles on road and improve the transportation system sustainability. The strategy of promoting public transportation in Oman will support decrease the usage of personal vehicles and reduce the consumption of more fuel and contribute to enhancing the economic development of the country.

Q3. How does transport sustainability affect Oman's economic growth?

Ans: The development of train facilities will support Oman in the future to enhance the effectiveness of the transportation system and improve economic growth. The strategy of pricing policies will support reducing the operational cost for the transportation industry and contribute to improving the economic development of the country.

Q4. What are the benefits of the transportation system in Oman?

Ans: There are different types of transportation systems are available in Oman like air, sea, and road. The improvement of the transportation system will help to enhance environmental protection, enhancement of social development, and improve the economy of the country. An efficient transportation sector is supportive for the country to provide more employment to the people, enhance the educational level of people, reduce air pollution, enhance the economic stability of Oman, strengthen the financial stability of each person, save energy, reduce the consumption of energy, improve the effectiveness of logistics system, protect the environment, and enhance the business growth of the companies.

\section{RECOMMENDATION AND CONCLUSION}

\section{A. Recommendations}

The following points are supportive for Oman to enhance the efficiency of the transportation system and achieve improvement in economic development.

- Oman's ministry of transport should invest and learn to adopt the latest technology in transportation modes such as the latest trend in the $21^{\text {st }}$ century the hyperloop, robot shuttles, electric vehicles, and other modes of transports that are eco-friendly.

- Oman's Ministry of transport should apply a comprehensive evaluation on the impacts of Omani vehicle ownership that if these modes of transports will create harm for the people and environment in this country, the government should increase the pricing of roads, regulate car 
ownership, and imposed fines for those smoke belchers vehicles of any kind.

- The Ministry of transport in Oman should invest more in the improvement of transport infrastructure throughout the Sultanate so that the economy will function effectively and that will ensure fast mobility of people here in Oman especially in terms of business engagements.

- The Ministry of transport in Oman should build a resilient supply chain activity focusing to reduce costs savings, reducing risks, adaptability, fast, and sustainability yielding Oman's economic productivity.

- The Ministry of transport in Oman should develop their existing employees (human capital) focusing to upgrade them on time punctuality at work, skills, and energy to achieve their ministerial goal effectively.

\section{B. Conclusion}

In view of the above points, this research analyzed the transportation issues in Oman towards the economic development sustainability of the country. The primary data used in this research by doing the activity of a questionnaire. The secondary data was collected through books, articles, online sites, and journals. The study resulted that the transportation improvement is effective to enhance the economic development in Oman. Moreover, there is a technology change every day and the advancement in technology is considered as the main challenge for the transportation industry in Oman.

The improvement in the transportation sector is very effective for the provision of more employment to the people in Oman and enhances the logistics system efficiency. In addition, there will be an improvement in the production capacity of the companies in accordance with the increase in the transportation system and it leads the economic development of Oman. the adoption of train facilities is an asset for Oman to improve the transportation system effectiveness in the future for the economic growth development. Furthermore, the government's willingness to invest more in transport infrastructure, human capital and eco-friendly transportation modes, and modern transportation solutions can bring the entire Sultanate towards a sustainable emerging marketplace.

Transportation has an important role in the economic development of a country. The economic development of the country is directly influenced by the improvement of the transportation sector. In addition, the issue in the transportation system causes the problem for the country towards the economic development. The sustainable development of the country is mainly focused on economic development and it is closely associated with the development of the transportation system. The development of the economy of Oman is directly involved with the transportation system. Furthermore, adequate changes in technology are one of the main problems faced by the transportation system in Oman.

The strategy of enhancing sustainability is effective to enhance the transportation system sustainability in Oman. Furthermore, usage of clean fuel, improvement of culture, and improvement in-vehicle technology will support to decrease the operational cost of the transportation sector and contribute to sustaining the economic development of Oman.
In addition, the availability of public transportation as part of transportation improvement will help the local people to make their local trips efficiently and enhance the people comfortable and contribute to enhancing the country's economic growth. The provision of low-cost transportation infrastructure to the people is effective for enhancing customer satisfaction and improve the economic development of the country.

It is easy to reduce the operational cost of the transportation industry with the support of effective pricing policies and it will support enhance the economic growth of Oman. the improvement in the infrastructure of Oman is effective to enhance the efficiency of the transportation system in Oman. In addition, towards the improvement of trade between other countries seaport has an important role and it contributes to improving the economic growth of Oman. Also, to improve the tourism activities in Oman the improvement of airport facilities is supportive, and it will contribute to improving the economy of Oman. Furthermore, one of the most important problems for the transportation and logistics sector companies in Oman is the lack of the talents and skills of their employees.

There will be an improvement in the supply chain activities with the support of an increase in transportation sustainability and this will support the companies to give the best output. Also, the improvement in electric vehicle infrastructure is very effective for Oman to enhance the efficiency of transportation sustainability. In addition, there are issues for transportation sector companies due to the process of Omanization like the provision of training to employees and increasing the financial liabilities of the firms. Furthermore, there will be an improvement in the Oman economy due to the increase in the road transportation system.

\section{ACKNOWLEDGMENTS}

Without any doubt, the author thanks warmly everyone who helped in guiding and supporting the research with knowledge and advice to complete and finish this paper. In addition, the author also extends his gratitude to his parents for their kind support to successfully finished this paper.

Special thanks to Dr. Adela P. Balasa's supervisor for her significant role in her constant, continuous supervision, guidance, and advice for completing the research.

Special gratitude and thanks also to the co-supervisor, Ms. Shima Ibrahim Al Maqbalia, for her guidance and constant co-supervision towards this paper.

\section{REFERENCES}

[1] S. Al Musalmy, “New public transport system: Will it have any takers?," 2014. [Online]. Available: http://www.muscatdaily.com/Archive/Oman/New-public-transportsystem-Will-it-have-any-takers-3p4v\#ixzz4SWi0eEDy. [Accessed: 24-Feb-2021].

[2] Al Kindi, N. Kazem, H. A. Raut, N. Chaichan, M. T., Al Asadi, K. A H., "Environmental Impact Assessment of traffic in Sohar, Oman." 6(7): 493-496: International Journal of Scientific \& Engineering Research, 2015.

[3] Abdul-Wahab, S. A., \& Fadlallah, S. O, "A study of the effects of vehicle emissions on the atmosphere of Sultan Qaboos University in Oman." 98: 158-167: Atmospheric Environment, 2014. 
[4] Brown, S., Hanson, S. and Nicholls, R.J., Implications of sea-level rise and extreme events around Europe: a review of coastal energy infrastructure. 122, 81-95: Climatic Change, 2014.

[5] J. J. Brogan et al., Freight Transportation Modal Shares: Scenarios for a Low-Carbon Future. 80 pp: Department of Energy, Washington, DC., 2013.

[6] R. Belwal, "People's Perception of Public Transport Services in Oman," Utm.my, 2013. [Online]. Available:

http://www.jurnalteknologi.utm.my/index.php/jurnalteknologi/article/ view/2140/1704. [Accessed: 24-Feb-2021].

[7] M. \&. K. P. Beecroft, Future prospects for personal security in travel by public transport. 38(1):131-148: Transportation planning and technology, 2015.

[8] K. \&. A. R. Button, Transportation and Economic Development Challenges, Cheltenham. Edward Elgar Publishing, 2011.

[9] J. Cidell, "The role of major infrastructure in subregional economic development: an empirical study of airports and cities." Journal of Economic Geography, 2015, 15(6), 1125-1144.

[10] Cairney \& Denny, What is qualitative research (Bloomsbury). International Journal of Social Research Methodology, 2014, 18, 117125.

[11] J. M. d. C. Canoquena, "Reconceptualising policy integration in road safety management." Transport Policy, 2013, 25(0): 61-80.

[12] Chee W.L. \& Fernandez J.L., Factors that Influence the Choice of Mode of Transport in Penang: A Preliminary Analysis Procedia. Social and Behavioral Sciences. 2013, 91, 120-127.

[13] R. Das, "Oman transport: Mwasalat to launch 118 buses next year," Timesofoman.com, 2016, 27 Nov. [Online]. Available: https://timesofoman.com/article/97390/Oman/Transport/Omantransport:-Mwasalat-to-roll-out-118-newbuses-\%20next-year. [Accessed: 24-Feb-2021].

[14] D. I. \&MacKinnon D., "Transport and economic development." Sage, London, UK: in J-P Rodrigue, T. Notteboom, T. and J. Shaw (eds.) The Sage Handbook of Transport Studies., 2013.

[15] Drevs, F., Tscheulin, D.K., Lindenmeier, J., Renner, S., Crowding-in or crowding out: An empirical analysis on the effect of subsidies on individual willingness-to-pay for public transportation. Transportation Research Part A: Policy and Practice, 2014, 59, 250-261.

[16] Ferrari L., Berlingerio M., Calabrese F., "Improving the accessibility of urban transportation networks for people with disabilities," Transportation Research Part C: Emerging Technologies, 2014, vol. 45 , pp. $27-40$.

[17] Ferro P.S. Behrens R. \& Wilkinson P., Hybrid urban transport systems in developing countries: Portents and prospects. Research in Transportation Economics, 2013, 39 (1)121-132.

[18] C. Furzer, "It's all about transformation, innovation, and communication." Public Transport International, 2013, 1: 4-6.

[19] K. Gwilliam, Cities on the move - Ten years after. Research in Transportation Economics. 2013, 40, (1), 3-18.

[20] Hamersma, Marije \& Tillema, Taede \& Sussman, Joseph \& Arts, Jos, "Residential satisfaction close to highways: The impact of accessibility, nuisances and highway adjustment projects,." Transportation Research Part A: Policy and Practice, Elsevier, 2014, vol. 59(C), pp. 106-121.

[21] Hickman, R., M. Givoni, D. Bonilla \& D. Banister (eds.), Handbook on Transport and Development. Cheltenham: Edward Elgar, 2015.

[22] I. M. M. \&. A. Y. Al Hadhrami, "Increased motorization and road traffic accidents in Oman." Journal of Emerging Trends in Economics and Management Sciences, 2012, 3(6):907.

[23] T. R. Lakshmanan, "The broader economic consequences of transport infrastructure investments." Journal of Transport Geography, 2011, Vol. 19, No. 1, pp. 1-12.

[24] S. Mitric, Urban transport lending by the World Bank: The last decade. Research in Transportation Economics. 2013, 40 (1), 19-33.

[25] Mugenda, G. A. \& Mugenda, M. O., Research Methods: Quantitative and Qualitative Approaches. Nairobi: Act Press, 2010.

[26] Musso, A., Piccioni, C., Tozzi M., and Godard G., Road transport elasticity: How fuel price changes can affect traffic demand on a toll motorway. Procedia - Social and Behavioral Sciences, 2013, 87, 85102.

[27] V. Nair, "Muscat residents welcome public transport revamp," Omanobserver.om, 2015, 30 May. [Online]. Available: https://www.omanobserver.om/muscat-residents-welcome-publictransport-revamp/. [Accessed: 24-Feb-2021].

[28] V. Nereim, "Oman plans public transport system to ease traffic woes," Thenationalnews.com, 2014, 22 Oct. [Online]. Available: https://www.thenationalnews.com/mena/oman-plans-public-transportsystem-to-ease-traffic-woes,/. [Accessed: 24-Feb-2021].

[29] ALSI, "The challenges in logistics and transportation industry in Oman," Alsioman.com, 30-Sep-2019. [Online]. Available: https://www.alsioman.com/logistics-transportation-challenges/. [Accessed: 27-Feb-2021].

[30] E. Pourmohammadi, "Oman transport: ONTC reveals its new brand identity "Mwasalat" Timesofoman.com, 08-Nov-2015. [Online]. Available:

http://timesofoman.com/article/71358/Oman/Transport/Oman-

National-Transport-Company-ONTC-hasrevealed-its-new-brandidentity-'Mwasalat'. [Accessed: 24-Feb-2021].

[31] J.-P. Rodrigue, "Transport and Development." New York: John Wiley \& Sons: The International Encyclopedia of Geography, 2017.

[32] J.-P. Rodrigue, "The Role of Transport and Communication Infrastructure in Realising Development Outcomes." The Palgrave Handbook of International Development. London: Palgrave Macmillan, 2016, pp. 595-614.

[33] Saunders, M., Lewis, P. and Thornhill, A., Research Methods for Business Students. Pearson Education Ltd, 2012.

[34] H. Singhry, An Extended Model of Sustainable Development from Sustainable Sourcing to Sustainable Reverse Logistics: A Supply Chain Perspective. International journal supply chain management, 2015, 4, (4), pp. 115-125.

[35] T. F. Welch, Equity in transport: The distribution of transit access and connectivity among affordable housing units. Transport Policy. 2013, 30, 283-293.

[36] Yin, Case Study Research: Design and Methods. 4thEd. Vol. 6: Applied Social Research Methods, 2010.

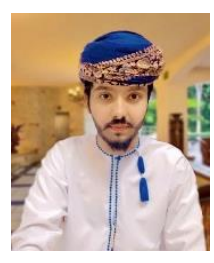

Omran Abdullah Salim Al-Mukhini was born in Sultanate of Oman, Sohar, November 26, 1996. The author has B.A in Logistics and Transport Management/ International Maritime College Oman, Suhar, Sultanate of Oman.

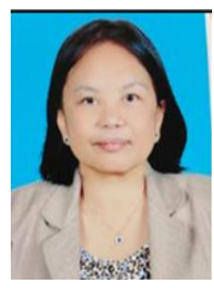

Adela P. Balasa is Doctor of Public Administration (DPA), The University of Manila, Manila, Philippines, October 2002. She is presently working as an Associate Professor of Economics at International Maritime College Oman, Sohar, Sultanate of Oman, from February 2009 up to now.

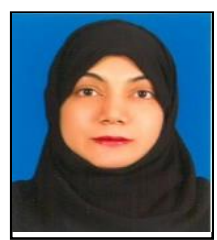

Mrs. Shaima Ibrahim Al Maqbalia had her bachelor's degree in Logistics and Transport Management at International maritime college Oman, in 2012. She is recently studying her master's degree in operations and supply chain management at Sultan Qaboos University, Muscat, Sultanate of Oman, an assistant Lecturer of Logistic Management and internship coordinator of training at International Maritime College Oman, Sohar, Sultanate of Oman. 